\title{
Investigation of Effective Mechanical Characteristics of Nanomodified Carbon-Epoxide Composite by Numerical and Analytical Methods
}

\section{M.O. Kaptakov}

Moscow Aviation Institute (National Research University), Volokolamskoeshosse, 4, 125993, Moscow, Russia $\underline{\text { mkaptakov@mail.ru }}$

Article History: Received: 11 January 2021; Accepted: 27 February 2021; Published online: 5 April 2021

\begin{abstract}
In this work, the mechanical properties of composite samples prepared using a conventional and nanomodified matrix were studied. The thickness of the monolayers in the samples was $0,2 \mu \mathrm{m}$. It was found in experiments, that the addition of fullerene soot as a nanomodifierled to an increase in the mechanical properties of the samples along the direction of reinforcement. At the same time, an improvement in the quality of the contact of the matrix with the fibers in the samples with the nanomodifier was observed: on the fracture surface, the nanomodified matrix envelops the fibers, while the usual matrix completely exfoliates. The obtained effects of changing the strength of composites can be associated, among other things, with a change in the level of residual stresses arising in composites during nanomodification. Analytical and numerical modeling methods are used to explain these effects.
\end{abstract}

Keywords: Mechanical properties, nanoparticles, modification, strength, polymers.

\section{Introduction}

The development of modern technology requires the creation of new structural materials with high elasticstrength characteristics, and, on their basis, structures with more effective weight data. The creation of polymer composites based on nano-modified binders has been one of the priority areas of research in the field of composite materials manufacturing technologies for many years[1-12]. Significant progress has been made in this area [13-21]. The development of composite materials that improve their operational limits is based on the reinforcement of two or more fibers into a single polymer matrix, which leads to an improved material system called hybrid composites with a wide variety of material properties [22-25]. When creating nanocomposites, the key tasks are the development of efficient, reliable, and affordable production technologies for mass production, which make it possible to obtain materials with stable mechanic characteristics[26-39]. The objective of this work is to identify the characteristics of elasticity and thermoelasticity of monolayers, which are realized in the resulting composites.

\section{Experimental studies of the mechanical properties of composites}

In the experiments, samples of composites obtained from carbon fibers and an epoxy binder and obtained from carbon fibers and a nano-modified epoxy binder containing $0.2 \mathrm{wt}$. \% fullerene soot produced by the company "Nanopolymer" (Russia) and particles of carbon black (soot). The samples differed in the mutual orientation of the carbon fiber layers. The used fullerene soot contains 10\% of C60 and C70 fullerenes and consists of 100\% carbon, that is, it does not contain other impurities. The density of soot is $0,3 \mathrm{~g} / \mathrm{cm}^{3}$. Epoxy binder EDT-10 (Russia) and carbon fibers HTA-40 (TohoTenax Co. Ltd.) were used to prepare composite samples. The fiber volume content was $50 \%$. The properties of the matrix fibers are presented in Tables 1 and 2 . For the nanomodified matrix, it is also known that Young's modulus was $2.5 \mathrm{GPa}$.

Table 1. Properties of NTA 40 fibers

\begin{tabular}{|l|l|l|}
\hline Characteristics & Unit & Value \\
\hline Elasticmodulus, E1 & $\mathrm{GPa}$ & 257 \\
\hline Elasticmodulus, E2 & $\mathrm{GPa}$ & 24 \\
\hline Shearmodulus, G12 & $\mathrm{GPa}$ & 16 \\
\hline Poisson'scoefficient, v21 & - & 0,279 \\
\hline Poisson'scoefficient, v23 & - & 0,49 \\
\hline CTE & $10^{-6} \cdot{ }^{\circ} \mathrm{C}^{-1}$ & $-0,1$ \\
\hline Density & $\mathrm{g} / \mathrm{cm}^{3}$ & 1,7 \\
\hline
\end{tabular}

Table 2. Properties of EDT matrix -10

\begin{tabular}{|l|l|l|}
\hline Characteristics & Unit & Value \\
\hline Elasticmodulus,E & $\mathrm{GPa}$ & 2 \\
\hline Poisson'scoefficient, $v$ & - & 0,4 \\
\hline CTE & $10^{-6} \cdot{ }^{\circ} \mathrm{C}^{-1}$ & 65 \\
\hline Density & $\mathrm{g} / \mathrm{cm}^{3}$ & 1,23 \\
\hline
\end{tabular}


Investigation of Effective Mechanical Characteristics of Nanomodified Carbon-Epoxide Composite by Numerical and Analytical Methods

The results of testing samples of composites made using a conventional and nano-modified matrix are presented in Table 3. The thickness of the monolayers in the samples was $0,2 \mu \mathrm{m}$. It was found in experiments that the addition of fullerene soot led to an increase in the mechanical properties of the samples along the direction of reinforcement. At the same time, an improvement in the quality of the contact of the matrix with the fibers in the samples with the nanomodifier was observed - on the fracture surface, the nanomodified matrix envelops the fibers (Fig. $1 \mathrm{a}, \mathrm{b}$ ), while the usual matrix completely exfoliates (Fig. $1 \mathrm{c}, \mathrm{d}$ ). The obtained effects of changing the strength of composites can be associated, among other things, with a change in the level of residual stresses that arise in composites during nanomodification.

Table 3. Test results of composite samples

\begin{tabular}{|l|l|l|l|l|}
\hline \multirow{3}{*}{ Sample } & Regularbinder & Withfiller & \\
\cline { 2 - 5 } & Elasticmodulus, & Tensilestrength, & Elasticmodulus, & Tensilestrength, \\
& $G P a$ & $M P a$ & $G P a$ & $M P a$ \\
\hline 1 & 128 & 1260 & 138 & 1526 \\
\hline 2 & 7 & 52 & 6 & 43 \\
\hline 3 & 72 & 764 & 66 & 579 \\
\hline 4 & 9 & 123 & 12 & 146 \\
\hline
\end{tabular}
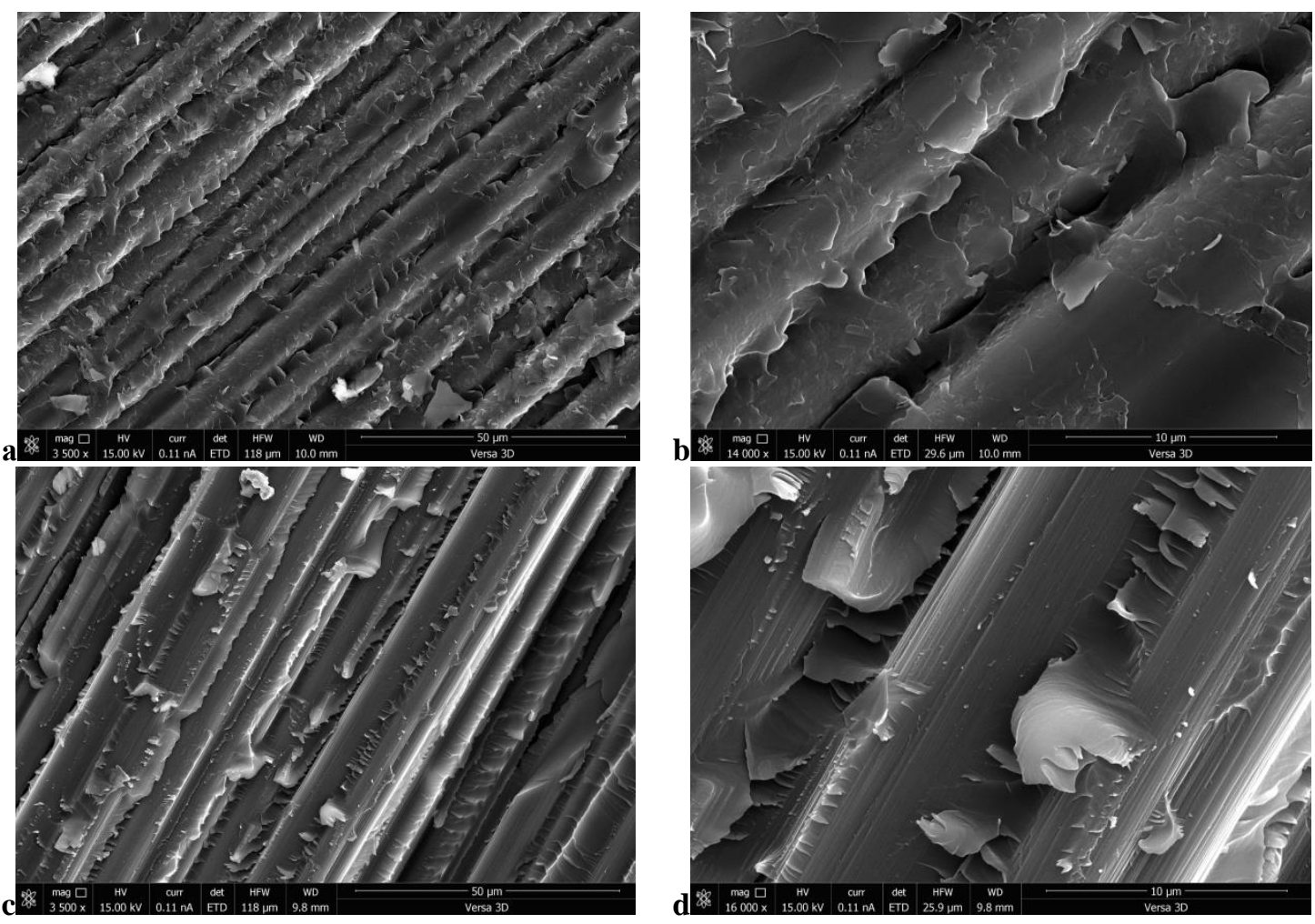

Fig. 1. Micrographs of the fracture surface of composites with nanomodified (a, b) and conventional (c, d)

Modeling the elastic properties of nanocomposites matrices.

To identify the elastic properties of a monolayer from the known values of the elastic moduli of composite samples with different reinforcement schemes, we will use the classical model of layered composites[29-33]. The effective modulus of elasticity of a layered composite with a symmetric reinforcement scheme can be found by the formula:

$E=\frac{1}{H}\left(A_{11}-\frac{A_{12}^{2}}{A_{22}}\right)$

Here $H=n h-$ thickness of a package composed of $n$ monolayers with a thickness $h, A_{i j}=h \sum_{k=1}^{n}\left(\bar{Q}_{i j}\right)_{k}-$ components of the stiffness matrix of a layered material for the case of a plane stress state formed by layers of equal thickness, $\left(\bar{Q}_{i j}\right)_{k}$ - reduced moduli of elasticity of the kth layer in the coordinate system of the package, 
determined on the basis of standard relations through the sought characteristics of the rigidity of monolayers and their orientation angles $\theta_{k}$. In matrix form, these relations can be represented in the following form:

$$
\left(\bar{Q}_{i j}\right)_{k}=[\bar{Q}]_{k}=[T]_{k}^{-1}[Q]_{k}[R]_{k}[T]_{k}[R]_{k}^{-1} \text {, }
$$

where:

$$
\begin{aligned}
& {[T]_{k}=\left(\begin{array}{ccc}
\cos ^{2} \theta_{k} & \sin ^{2} \theta_{k} & 2 \cos \theta_{k} \sin \theta_{k} \\
\sin ^{2} \theta_{k} & \cos ^{2} \theta_{k} & -2 \cos \theta_{k} \sin \theta_{k} \\
-\cos \theta_{k} \sin \theta_{k} & \cos \theta_{k} \sin \theta_{k} & \cos ^{2} \theta_{k}-\sin ^{2} \theta_{k}
\end{array}\right)} \\
& {[R]=\left(\begin{array}{lll}
1 & 0 & 0 \\
0 & 1 & 0 \\
0 & 0 & 2
\end{array}\right),[Q]_{k}=\left(\begin{array}{ccc}
Q_{11} & Q_{12} & 0 \\
Q_{12} & Q_{22} & 0 \\
0 & 0 & Q_{66}
\end{array}\right)} \\
& Q_{11}=E_{1} /\left(1-v_{12} v_{21}\right), Q_{22}=E_{2} /\left(1-v_{12} v_{21}\right), Q_{12}=v_{12} E_{2} /\left(1-v_{12} v_{21}\right), \quad Q_{66}=G_{12},
\end{aligned}
$$

whereby $v_{21} E_{1}=v_{12} E_{2}$.

Thus, the desired characteristics of a monolayer are elastic moduli along and across the fibers $E_{1}$ and $E_{2}$, Poisson's ratio $v_{12}$ and in-plane shear modulus $G_{12}$. These values are identified from the conditions for the minimum standard deviation of the calculation results and experimental data for the elastic moduli of the composites presented in Table 2.3. Accordingly, consider the following function:

$$
f\left(E_{1}, E_{2}, v_{12}, G_{12}\right)=\frac{1}{2} \sqrt{\left(\Delta E_{0}\right)^{2}+\left(\Delta E_{90}\right)^{2}+\left(\Delta E_{ \pm 45}\right)^{2}+\left(\Delta E_{0 / 90}\right)^{2}},
$$

where $\Delta E \ldots$ - this is the difference between the experimentally found value of the elastic modulus of the composite in a given direction (Table 3) and its calculated value determined by the expression (1).

Variable values $E_{1}, E_{2}, v_{12}$ and $G_{12}$, at which function (2) reaches a minimum are the sought characteristics of the monolayer.

To determine the properties of unidirectional layers of fiber composites, we use the model of a cylindrical inclusion. To take into account the effect of the dispersed filler (fullerene soot), it is necessary to take into account that the nanomodified matrix additionally contains spherical inclusions, which are particles of carbon black and fullerenes C60 and C70.

Based on the initial experimental data, it is known that the fiber volume content is $50 \%$. The content of fullerene soot in the matrix is $0,2 \mathrm{wt}$. \%. Taking into account the known density of the epoxy matrix and fullerene soot, we obtain that the volumetric content of the filler in the matrix is $0,82 \%$. In this case, the content of fullerenes is only $1 / 10$ of this value, that is, $0,082 \%$. The remaining $0,738 \%$ is carbon black.

The fiber diameter is $7 \mu \mathrm{m}$. The size of fullerenes is about $1 \mathrm{~nm}$, and of carbon black particles - 50-1000 nm. For carbon black particles, when constructing representative fragments of material for numerical calculations, we will set the normal size distribution.

The properties of the matrix and fibers are known (Tables 1 and 2). The elastic modulus of fullerenes is assumed to be approximately equal to $1 \mathrm{TPa}$, and the Poisson's ratio is 0,35 . For carbon black particles, the corresponding characteristics are taken equal to $80 \mathrm{GPa}$ and 0,3 . To assess the thermoelastic characteristics of monolayers, the coefficient of thermal expansion of the filler particles is assumed to be $5 \cdot 10^{-6} \mathrm{C}^{-1}$.

An analytical calculation to determine the effective elastic properties of a monolayer will be carried out in the Digimat-MF module using the Mori-Tanaka averaging method. Separately, we will also evaluate the effect of the filler on the elastic modulus of the matrix, considering the material containing only fullerene soot as inclusions. Based on these calculations, we will determine the "effective" volumetric content of inclusions, taking into account the influence of interphase layers formed around the inclusions. The influence of these layers, as will be shown below, cannot be neglected, since in this case underestimated values of the elastic characteristics of the matrix will be obtained. Therefore, in fact, knowing the modulus of elasticity of the nanomodified matrix from experiments, the content of the filler will be selected such that the calculation and experiment will coincide. The found value of the effective volumetric content of inclusions is further used in analytical and numerical calculations of the properties of a monolayer.

Numerical calculations will be carried out using the Digimat-FE module. The size of a cubic representative fragment was set by the system automatically. The effective elastic properties were calculated by determining the ratio of the volume-averaged representative fragment of the stress level to a given value of homogeneous 
deformations. In this case, the boundary conditions and the geometry of the fragment itself are periodic. The calculations were carried out using the finite element method.

An example of a representative fragment of a unidirectional composite containing a dispersed filler is shown in Fig. 2 a. This illustration shows only reinforcing fibers and carbon black particles. Fullerenes, even with a very low volumetric content (less than $0,1 \%$ ), are contained in such a fragment in a very large amount, and it is impossible to model their effect at this scale level. For example, a cubic fragment of a $1 \mu \mathrm{m}$ matrix contains more than 400 thousand fullerenes for a given volumetric content. Therefore, in particular, the nano-modified binder is black, while the usual binder is yellow. To model such materials, it is necessary to resort to multiscale approaches and to carry out a consistent determination of effective properties at various scale levels. This task is greatly simplified if the properties of the nanomodified matrix are known from experiments. In particular, it is known that its Young's modulus is $2.5 \mathrm{GPa}$. The missing characteristic is Poisson's ratio, which can be approximately taken unchanged, or estimated on the basis of analytical calculations using the found value of the "effective" volumetric content of the filler, which was done. Further, it suffices to numerically solve the averaging problem on a representative fragment containing only fibers (Fig. 2 b).

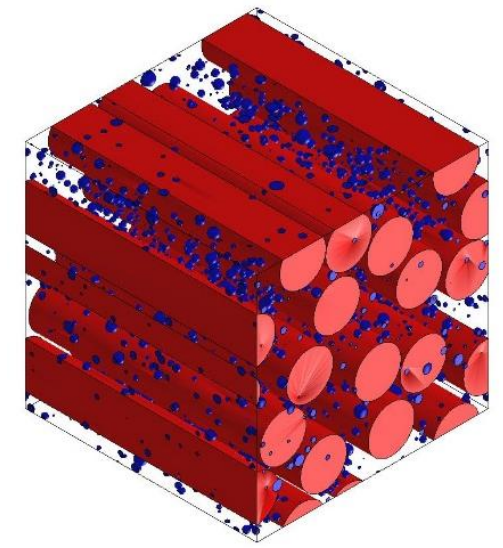

a

Fig. 2. Examples of cubic representative fragments of a unidirectional layer based on a matrix with a filler (b) and a homogeneous matrix (a). Fragment size $35 \mu \mathrm{m}$.

The solution to the problem of minimizing function (2) within the framework of the macromechanical approach was built using the Matlab system. In the process of searching for the minimum of function (2), the restriction was imposed that the Poisson's ratio of a unidirectional layer $v_{12}$ cannot exceed the Poisson's ratio of the matrix. Without this condition, minimization led to the determination of obviously overestimated values $v_{12}$ for composites with the original matrix. Based on the available experimental data (Table 3), the following characteristics of the elasticity of the monolayer were found based on the initial matrix:

$E_{l}=131 \mathrm{GPa}, E_{2}=8.3 \mathrm{GPa}, v_{12}=0.4, G_{12}=2.4 \mathrm{GPa}$

and based on nano-modified matrix:

$E_{l}=136 \mathrm{GPa}, E_{2}=4 \mathrm{GPa}, v_{12} \approx 0, G_{12}=3.3 \mathrm{GPa}$.

Within the micromechanical approach, the characteristics of a unidirectional layer without nanoparticles were determined on the basis of the classical solution of the averaging problem for the model of a cylindrical inclusion by the Mori-Tanaka method, and they were:

$E_{l}=129 . \mathrm{GPa}, E_{2}=5 . \mathrm{GPa}, v_{12}=0.33, G_{l 2}=1 . \mathrm{GPa}$,

$\alpha_{1}=4.5 \cdot 10^{-7} \mathrm{C}^{-1}, \alpha_{2}=4.2 \cdot 10^{-5} \mathrm{C}^{-1}$

To obtain an analytical assessment of the properties of the nanomodified monolayer, the "effective" volumetric content of fullerene soot in the matrix was preliminarily determined, at which the calculated value of the effective Young's modulus of the nanomodified matrix coincides with the known experimental value (2,5 GPa). It was found that if we do not take into account interfacial effects, then the calculation predicts the effective Young's modulus equal to 2,04 GPa, with an initial value of $2 \mathrm{GPa}$. That is, with such a low content $(0.82 \%)$ of even very hard inclusions, they should not have a significant effect on the properties of the material. The experimentally found increase in the matrix modulus can be explained by the influence of hardened and rigid interphase zones formed around the inclusions. For an approximate assessment of their influence, the concept of "effective" volumetric content of inclusions is introduced. It is assumed that the properties of the interphase zones and inclusions are the same, and the calculation should use the value of the "effective" volumetric content of inclusions, which is the sum of their real volumetric content and the content of interfacial zones. This value was approximately $10 \%$ for the considered composite. In this case, the predicted Young's modulus of the modified matrix is $2.5 \mathrm{GPa}$, Poisson's ratio is 0,39 , and the thermal expansion coefficient is $5.76 \cdot 10-5 \mathrm{C}-1$. Further, taking into account the "effective" content of inclusions, the following characteristics of a unidirectional layer with nanoparticles were found: 
$E_{l}=130 \mathrm{GPa}, E_{2}=5.9 \mathrm{GPa}, v_{12}=0.33, G_{12}=2.2 \mathrm{GPa}$

$\alpha_{1}=5.3 \cdot 10^{-7} \mathrm{C}^{-1}, \alpha_{2}=3.3 \cdot 10^{-5} \mathrm{C}^{-1}$

As a result of numerical modeling using three-dimensional representative fragments (Fig. 2b), the following values of the characteristics of monolayers were found. No added nanoparticles:

$E_{l}=124.8 \mathrm{GPa}, E_{2}=4.9 \mathrm{GPa}, v_{12}=0.33, G_{12}=1.5 \mathrm{GPa}$,

$\alpha_{1}=5 \cdot 10^{-7} \mathrm{C}^{-1}, \alpha_{2}=4.3 \cdot 10^{-5} \mathrm{C}^{-1}$

For nano-modified layer:

$E_{l}=125 \mathrm{GPa}, E_{2}=6 \mathrm{GPa}, v_{12}=0.33, G_{12}=1.8 \mathrm{GPa}$

$\alpha_{1}=5.6 \cdot 10^{-7} \mathrm{C}^{-1}, \alpha_{2}=3.8 \cdot 10^{-5} \mathrm{C}^{-1}$

When using the characteristics of monolayers (3) and (4) found within the framework of the macromechanical approach, the standard deviation of the calculation results from experiments is $1.6 \mathrm{GPa}$ for a conventional matrix and $2.5 \mathrm{GPa}$ for a nanomodified matrix. The corresponding deviations for characteristics (5) and (6), found as a result of micromechanical modeling and analytical calculations, were $2.6 \mathrm{GPa}$ and $4.5 \mathrm{GPa}$. For the sets of characteristics (7) and (8) found in numerical calculations, deviations of 4,3 GPa and 6,7 GPa were obtained.

Comparison of the calculated results obtained within the framework of macro- and micromechanical modeling and experimental data is shown in Fig. 3. Shown here are the values of the elastic moduli of composites with different reinforcement schemes, found experimentally and theoretically based on the identified properties of monolayers (3) - (8).
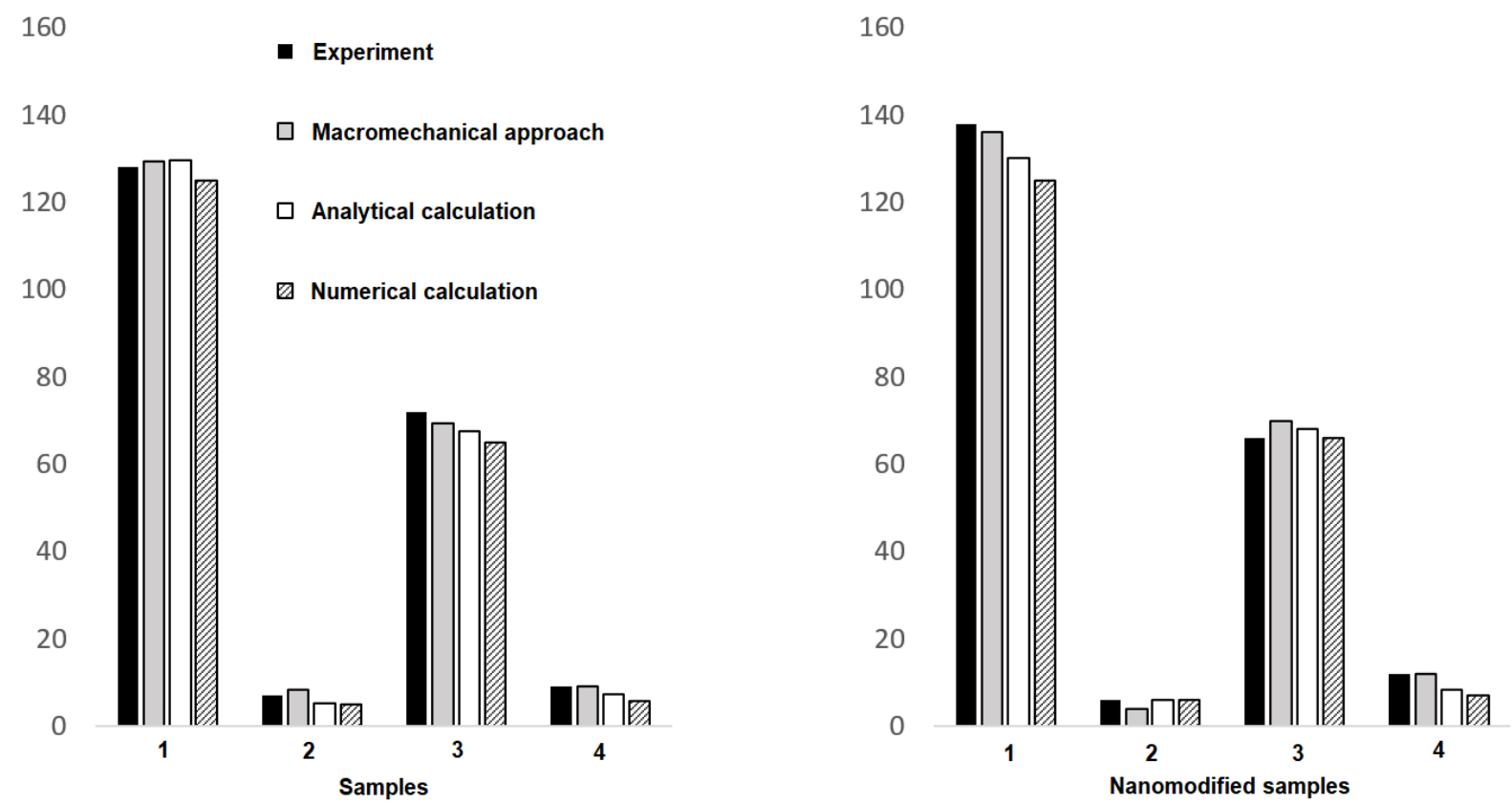

Fig. 3. Comparison of the experimental values and results of calculations of the elastic moduli of composites based on the conventional (a) and nanomodified matrix (b) taking into account the identified values of the elastic moduli of the monolayer. Vertical axis scale in GPa.

\section{Conclusions}

Based on the results of experimental studies, the effective characteristics of a monolayer made of a composite material based on both conventional and nanomodified matrices were determined, and a solution to the corresponding inverse problem was obtained. It was found that the addition of nanoparticles within the recommended standard range of $10 \%$ leads to a slight increase in the longitudinal elastic modulus and shear modulus of the monolayer. In this case, there is an almost twofold decrease in the elastic modulus in the transverse direction and a decrease to zero Poisson's ratio. The reliability of the developed numerical models is confirmed by a good correlation between the results of both numerical and analytical solutions and the obtained experimental data on the study of the thermomechanical characteristics of nanomodified materials.

\section{Acknowledgements}

This work has been carried out with the financial support of Russian Science Foundation, project No. 20-1900395 .

\section{References}

1. C. Schaller, T. Schauer, K. Dirnberger, C.D. Eisenbach. Synthesis and stabilizing properties of amphipolar polyelectrolytes. Eur. Phys. J., 2001, E 6, pp. 365-376.

2. C. Schaller, A. Schoger, K. Dirnberger, T. Schauer, C.D. Eisenbach. Stabilizing pigments in full-mixingsystems, Macromol. Symp., 2002, Vol. 179, pp. 173-188. 
Investigation of Effective Mechanical Characteristics of Nanomodified Carbon-Epoxide Composite by Numerical and Analytical Methods

3. C. Schaller, T. Schauer, K. Dirnberger, C.D. Eisenbach. Synthesis and properties of hydrophobically modified water-borne polymers for pigment stabilization, Progress in Organic Coatings, 1999, Vol. 35(14), pp. 63-67.

4. O.A. Butusova. Surface Modification of Titanium Dioxide Microparticles Under Ultrasonic Treatment, International Journal of Pharmaceutical Research, 2020, Vol. 12, I. 4, pp. 2292-2296.

5. O.A. Butusova. Stabilization of Carbon Microparticles by High-Molecular Surfactants, International Journal of Pharmaceutical Research, 2020, Vol. 12, Supplementary Issue 2, pp. 1147-1151.

6. O.A. Butusova. Vinyl Ether Copolymers as Stabilizers of Carbon Black Suspensions, International Journal of Pharmaceutical Research, 2020, Vol. 12, Supplementary Issue 2, pp. 1152-1155.

7. O.A. Butusova. Adsorption Behaviour of Ethylhydroxyethyl Cellulose on the Surface of Microparticles of Titanium and Ferrous Oxides, International Journal of Pharmaceutical Research, 2020, Vol. 12, Supplementary Issue 2, pp. 1156-1159.

8. A.N. Tarasova. Vibration-based Method for Mechanochemical Coating Metallic Surfaces, International Journal of Pharmaceutical Research, 2020, Vol. 12, Supplementary Issue 2, pp. 1160-1168.

9. A.N. Tarasova. Effect of Reagent Concentrations on Equilibria in Water-Soluble Complexes, International Journal of Pharmaceutical Research, 2020, Vol. 12, Supplementary Issue 2, pp. 1169-1172.

10. A.N. Tarasova. Effect of Vibration on Physical Properties of Polymeric Latexes, International Journal of Pharmaceutical Research, 2020, Vol. 12, Supplementary Issue 2, pp. 1173-1180.

11. B.A. Garibyan. Mechanical Properties of Electroconductive Ceramics, International Journal of Pharmaceutical Research, 2020, Vol. 12, Supplementary Issue 2, pp. 1825-1828.

12. B.A. Garibyan. Enhancement of Mechanical Properties of Inorganic Glass under Ultrasonic Treatment, International Journal of Pharmaceutical Research, 2020, Vol. 12, Supplementary Issue 2, pp. 1829-1832.

13. B.A. Garibyan. Modelling of Technical Parameters of Discharge Reactor for Polymer Treatment, International Journal of Pharmaceutical Research, 2020, Vol. 12, Supplementary Issue 2, pp. 1833-1837.

14. Yu.V. Ioni. Synthesis of Metal Oxide Nanoparticles and Formation of Nanostructured Layers on Surfaces under Ultrasonic Vibrations, International Journal of Pharmaceutical Research, 2020, Vol. 12, Issue 4, pp. 3432-3435.

15. Yu.V. Ioni, A. Ethiraj. Study of Microparticles Surface Modification by Electrokinetic Potential Measuring, International Journal of Pharmaceutical Research, 2020, Vol. 12, Issue 4, pp. 3436-3439.

16. Yu.V. Ioni. Effect of Ultrasonic Treatment on Properties of Aqueous Dispersions of Inorganic and Organic Particles in Presence of Water-Soluble Polymers, International Journal of Pharmaceutical Research, 2020, Vol. 12, Issue 4, pp. 3440-3442.

17. Yu.V. Ioni, A. Ethiraj. New Tailor-Made Polymer Stabilizers for Aqueous Dispersions of Hydrophobic Carbon Nanoparticles, International Journal of Pharmaceutical Research, 2020, Vol. 12, Issue 4, pp. 3443-3446.

18. Yu.V. Ioni. Nanoparticles of noble metals on the surface of graphene flakes, Periodico Tche Quimica, 2020, Vol. 17, No. 36, pp. 1199-1211.

19. N.A. Bulychev, M.A. Kazaryan. Optical Properties of Zinc Oxide Nanoparticles Synthesized in Plasma Discharge in Liquid under Ultrasonic Cavitation, Proceedings of SPIE, 2019, Vol. 11322, article number 1132219.

20. N.A. Bulychev, A.V. Ivanov. Effect of vibration on structure and properties of polymeric membranes, International Journal of Nanotechnology, 2019, Vol. 16, Nos. 6/7/8/9/10, pp. $334-343$.

21. N.A. Bulychev, A.V. Ivanov. Nanostructure of Organic-Inorganic Composite Materials Based on Polymer Hydrogels, International Journal of Nanotechnology, 2019, Vol. 16, Nos. 6/7/8/9/10, pp. $344-$ 355 .

22. N.A. Bulychev, A.V. Ivanov. Study of Nanostructure of Polymer Adsorption Layers on the Particles Surface of Titanium Dioxide, International Journal of Nanotechnology, 2019, Vol. 16, Nos. 6/7/8/9/10, pp. $356-365$.

23. Bulychev N. A., Kuznetsova E.L., Bodryshev V. V.Rabinskiy L.N. Nanotechnological aspects of temperature-dependent decomposition of polymer solutions, Nanoscience and Technology: An International Journal, 2018, Vol. 9 (2), p.91-97.

24. Bulychev, N.A., Rabinskiy, L.N. Ceramic nanostructures obtained by acoustoplasma technique//Nanoscience and Technology: An International Journal, 2019, 10(3), p. 279-286.

25. Bulychev, N.A., Rabinskiy, L.N., Tushavina, O.V. Effect of intense mechanical vibration of ultrasonic frequency on thermal unstable low-temperature plasma// Nanoscience and Technology: An International Journal, 2020, 11(1), p. 15-21.

26. Anikin V.A., Vyshinsky V.V., Pashkov O.A., et al. Using the maximum pressure principle for verification of calculation of stationary subsonic flow. Herald of the Bauman Moscow State Technical University, Series Mechanical Engineering, 2019, no. 6, pp. 4-16.

27. Formalev, V.F., Kartashov, É.M., Kolesnik, S.A. On the Dynamics of Motion and Reflection of Temperature Solitons in Wave Heat Transfer in Limited Regions // Journal of Engineering Physics and Thermophysics, 2020, 93(1), p. 10-15. 
28. Formalev, V.F., Bulychev, N.A., Kuznetsova, E.L., Kolesnik, S.A. The Thermal State of a Packet of Cooled Microrocket Gas-Dynamic Lasers // Technical Physics Letters, 2020, 46(3), p. 245-248.

29. Rabinskiy, L.N., Tushavina, O.V., Formalev, V.F. Mathematical modeling of heat and mass transfer in shock layer on dimmed bodies at aerodynamic heating of aircraft// Asia Life Sciences, 2019, (2), p. 897911.

30. Antufev, B.A., Egorova, O.V., Rabinskiy, L.N. Quasi-static stability of a ribbed shell interacting with moving load// INCAS Bulletin, 2019, 11, p. 33-39.

31. Bodryshev, V.V., Babaytsev, A.V., Rabinskiy, L.N. Investigation of processes of deformation of plastic materials with the help of digital image processing// Periodico Tche Quimica, 2019, 16(33), p. 865-876.

32. Astapov, A.N., Kuznetsova, E.L., Rabinskiy, L.N. Operating capacity of anti-oxidizing coating in hypersonic flows of air plasma//Surface Review and Letters, 2019, 26(2), 1850145 p.

33. Rabinskiy, L.N., Sitnikov, S.A. Development of technologies for obtaining composite material based on silicone binder for its further use in space electric rocket engines// Periodico Tche Quimica, 2018, 15(Special Issue 1), p. 390-395.

34. Rabinskiy, L.N., Tushavina, O.V., Starovoitov, E.I. Study of thermal effects of electromagnetic radiation on the environment from space rocket activity // INCAS Bulletin, 2020, 12(Special Issue), p. 141-148.

35. Babaytsev, A.V., Orekhov, A.A., Rabinskiy, L.N. Properties and microstructure of AlSi10Mg samples obtained by selective laser melting// Nanoscience and Technology: An International Journal, 2020, 11(3), p. 213-222.

36. Egorova, O.V., Kyaw, Y.K. Solution of inverse non-stationary boundary value problems of diffraction of plane pressure wave on convex surfaces based on analytical solution//Journal of Applied Engineering Science, 2020, 18(4), p. 676-680.

37. Rabinskiy, L.N., Tushavina, O.V. Problems of land reclamation and heat protection of biological objects against contamination by the aviation and rocket launch site // Journal of Environmental Management and Tourism, 2019, 10(5), p. 967-973.

38. Astapov, A.N., Lifanov, I.P., Rabinskiy, L.N. Perspective Heat-Resistant Coating for Protection of Cf/SiC Composites in Air Plasma Hypersonic Flow//High Temperature, 2019, 57(5), p. 744-752.

39. Dobryanskiy, V.N., Rabinskiy, L.N., Tushavina, O.V. Validation of methodology for modeling effects of loss of stability in thin-walled parts manufactured using SLM technology // Periodico Tche Quimica, 2019, 16(33), p. 650-656.

$\mathrm{S}$ 